\title{
An insight into the sialotranscriptome and virome of Amazonian anophelines
}

\author{
Vera Margarete Scarpassa ${ }^{1}$, Humbeto Julio Debat ${ }^{2}$, Ronildo Baiatone Alencar ${ }^{1}$, José Ferreira Saraiva ${ }^{1}$, Eric Calvo ${ }^{4}$, \\ Bruno Arcà $^{3}$ and José M. C. Ribeiro ${ }^{4 *}$
}

\begin{abstract}
Background: Saliva of mosquitoes contains anti-platelet, anti-clotting, vasodilatory, anti-complement and antiinflammatory substances that help the blood feeding process. The salivary polypeptides are at a fast pace of evolution possibly due to their relative lack of structural constraint and possibly also by positive selection on their genes leading to evasion of host immune pressure.

Results: In this study, we used deep mRNA sequence to uncover for the first time the sialomes of four Amazonian anophelines species (Anopheles braziliensis, A. marajorara, A. nuneztovari and A. triannulatus) and extend the knowledge of the A. darlingi sialome. Two libraries were generated from A. darlingi mosquitoes, sampled from two localities separated $\sim 1100 \mathrm{~km}$ apart. A total of 60,016 sequences were submitted to GenBank, which will help discovery of novel pharmacologically active polypeptides and the design of specific immunological markers of mosquito exposure. Additionally, in these analyses we identified and characterized novel phasmaviruses and anpheviruses associated to the sialomes of A. triannulatus, A. marajorara and A. darlingi species.

Conclusions: Besides their pharmacological properties, which may be exploited for the development of new drugs (e.g. anti-thrombotics), salivary proteins of blood feeding arthropods may be turned into tools to prevent and/or better control vector borne diseases; for example, through the development of vaccines or biomarkers to evaluate human exposure to vector bites. The sialotranscriptome study reported here provided novel data on four New World anopheline species and allowed to extend our knowledge on the salivary repertoire of $A$. darlingi. Additionally, we discovered novel viruses following analysis of the transcriptomes, a procedure that should become standard within future RNAseq studies.
\end{abstract}

Keywords: Vector biology, Mosquitoes, Malaria, Virus, Salivary glands, Transcriptome

\section{Background}

Anopheline mosquitoes (Diptera: Culicidae: Anophelinae) of the Anopheles Meigen, 1818 genus are important in public health because they are vectors of human malaria parasites in addition to arboviruses. In Brazil they are popularly known as "muriçoca", "mosquito prego", "suvela", "pernilongo", and "carapanã" [1]. Their development comprise the stages of egg, larvae (four instars), and pupae, which are aquatic, while the adult stage is terrestrial. Both male and female adults feed on carbohydrates from flowers and fruits; however, only females are hematophagous, using the proteins found in

\footnotetext{
* Correspondence: jribeiro@niaid.nih.gov

${ }^{4}$ Laboratory of Malaria and Vector Research, National Institute of Allergy and Infectious Diseases, Bethesda, MD, USA

Full list of author information is available at the end of the article
}

host blood for the production and development of their eggs [2]. While feeding blood, they can transmit pathogens to their hosts.

Currently, the Anopheles genus includes 465 formally recognized species, which are subdivided into seven subgenera: Anopheles (cosmopolitan, 182 species), Baimaia (Oriental, one species), Cellia (Old World, 220 species), Kerteszia (Neotropical, 12 species), Lophopodomyia (Neotropical, six species), Nyssorhynchus (Neotropical, 39 species), and Stethomyia (Neotropical, five species) [3]. Worldwide, the primary vectors of human malaria parasites belong to the subgenera Anopheles, Cellia, Kerteszia and Nyssorhynchus.

In the Americas, the dominant vector species belong to the Anopheles (three species) and Nyssorhynchus (six species) subgenera [4]. Among species of the subgenus

(c) The Author(s). 2019 Open Access This article is distributed under the terms of the Creative Commons Attribution 4.0 International License (http://creativecommons.org/licenses/by/4.0/), which permits unrestricted use, distribution, and reproduction in any medium, provided you give appropriate credit to the original author(s) and the source, provide a link to the Creative Commons license, and indicate if changes were made. The Creative Commons Public Domain Dedication waiver (http://creativecommons.org/publicdomain/zero/1.0/) applies to the data made available in this article, unless otherwise stated. 
Nyssorhynchus, Anopheles darlingi is the primary vector in Brazil, particularly in the Brazilian Amazon, and in other countries in South America [4, 5]. The remaining dominant vector species are A. albimanus, a member of the A. albitarsis complex, A. marajoara, A. aquasalis, and A. nuneztovari [4]. Other species of the Nyssorhynchus subgenus may be secondary local vectors or were found naturally infected with malaria parasite, such as $A$. benarrochi, A. rangeli, A. oswaldoi s.l., A. strodei, A. rondoni, A. trinkae, A. braziliensis, A. triannulatus, and $A$. mattogrossensis [6, 7].

Anopheles darlingi is one of the most anthropophilic and efficient malaria vector in the Neotropical region, particularly in the Brazilian Amazon region [5, 8]. It is mainly a riverine mosquito, amply distributed in the rainforest but also it is found in other regions from Brazil, with exception of the dry areas of northeastern region. Anopheles darlingi also efficiently adapts in areas of deforestation and altered environments, favoring its abundance and expansion and consequently triggering malaria outbreaks. Adults of this species bite throughout the night $[7,8]$, however, often two biting peaks have been observed, one at sunset and the other at dawn. Specimens of $A$. darlingi have been captured in both indoor and outdoor environments, with predominance for the later [8].

Anopheles marajoara is a member of the A. albitarsis complex. In the past, it was believed that $A$. marajoara was a secondary or local vector of minor importance. However, studies conducted in peri-urban areas of the city of Macapá, in the state of Amapá, Brazil, demonstrated that it can be a significant regional vector [9-11] as well as in Boa Vista, in the state of Roraima [12]. Supporting these findings, in the District of Coração, state of Amapá, A. marajoara was the most frequent species, together with $A$. darlingi and $A$. braziliensis, showing anthropophilic behavior and being captured in both indoor and outdoor environments $[13,14]$.

Previous studies have reported $A$. braziliensis as a zoophilic species with little or no importance in malaria transmission $[1,15]$ or as a secondary vector [5]. It has, however, been found infected with human malaria parasites in the states of Amazonas [8, 16], Amapá [9], Rondônia [17], and Roraima [12]. Curiously, in the District of Coração, state of Amapá, A. braziliensis was one of the three most abundant and anthropophilic species. It was captured in both indoor and outdoor environments, although it was more abundant outdoors [14]. Thus, A. braziliensis may play some role in malaria transmission when at high density.

Anopheles triannulatus sensu lato is predominantly zoophagic, exophilic, and is often found in the forest of the Brazilian Amazon region, but also it is easily found in the edge of forests. However, A. triannulatus s.l. has been reported with human malaria parasites in different regions of Brazil [7, 11, 18], as well as Peru and Venezuela [19, 20]; however, due to its behavior and habitat it has been recognized as a secondary vector.

Currently, Anopheles nuneztovari is recognized as a species complex, where $A$. nuneztovari s.s. is incriminated as an important human malaria vector in Colombia and Venezuela, showing endo and exophagic behaviors, and elevated levels of anthropophily and infection rate $[21,22]$. On the other hand, the Brazilian populations of $A$. nuneztovari s.l. are predominantly zoophagic; however, this species has been reported to be infected with Plasmodium spp. in five states of the Brazilian Amazon region [6, 7, 23], and it was incriminated as a local vector in the state of Amapá, Brazil [11]. Based on recent studies, $A$. nuneztovari s.l. may consist of two or more species within the Brazilian Amazon [24, 25], likely with different susceptibility to malaria parasites.

From the five species mentioned above, only $A$. darlingi has been studied under genomic and proteomic approaches, including transcriptome salivary gland analyses [26, 27]. In this study, we present next generation sequencing and sialotranscriptome approaches to investigate the salivary protein composition of five anopheline species from the Brazilian Amazon region, which include two samples of $A$. darlingi, an important malaria vector in this region, Anopheles marajoara, an important local malaria vector, and Anopheles nuneztovari, Anopheles triannulatus, and Anopheles braziliensis, secondary malaria vectors. Additionally, we discuss the evolutionary aspects of these secreted salivary compounds with other anopheline salivary protein previously studied. These protein sequences may help identification by mass spectrometry of polypeptides of pharmacological interest, or to help in the design of immunological markers of vector exposure.

The Anopheles virus landscape has been scarcely studied. The O'nyong-nyong arbovirus is the only Anopheles vectored virus yet reported, and the insect specific viruses of most Anophelines have been barely explored [28]. Here, by assessing mosquito sialotranscriptome data, we were able to identify and characterize three novel viruses associated to $A$. triannulatus, $A$. marajoara, and $A$. darlingi species. The detected viruses correspond to emergent clades of insect-specific viruses, predominantly hosted by mosquitoes.

\section{Results and discussion}

\section{General aspects of the assemblies}

The five anopheline species used in this study were collected in the Brazilian Amazon region (see Fig. 1 and Additional file 1: Table S1). Following extraction of salivary RNA of the organisms using RNeasy, and determination of their quality by a Bioanalyzer Nano Chip, 


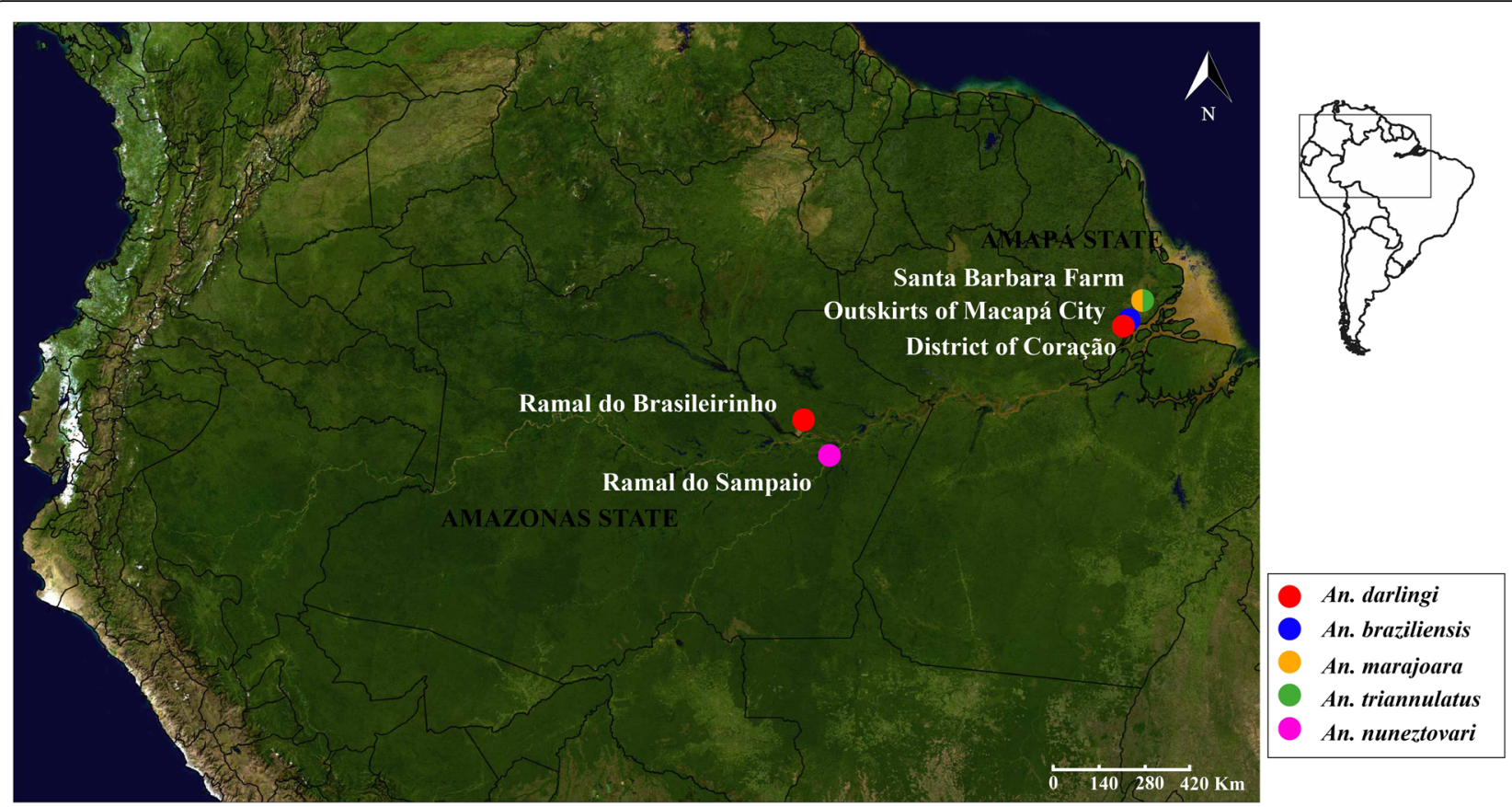

Fig. 1 Map showing the locations sampled for anopheline mosquitoes. The map was obtained from the site SimpeMappr, http://www.simplemappr.net/ \#tabs=6 and is on public domain

messenger mRNA was purified using an oligo-dT protocol. This was used to make the cDNA libraries using the NEBNExt Ultra Directional RNA kit, which were sequenced in an Illumina Hiseq 2500 DNA sequencer (for details see the methods section). Over 115 million reads were obtained for each of the A. darlingi libraries, and from 41 to 76 million reads for the other 4 libraries (Additional file 1: Table S2 and S3). From $\sim 6$ to 38 thousand CDS were extracted from each of the five assemblies, varying in average from 615 to $1200 \mathrm{nt}$ in length (Additional file 1: Table S4).

\section{Classification of transcripts coding for putative secreted proteins \\ General considerations}

Based on our previous review on the sialome of nematocera blood suckers [29], as well as on the most recent analysis of anopheline sialomes [30], we classified and retrieved 723 full length or near full length transcripts from the five anopheline species under study. After removing some redundant sequences (by restricting sequences within $98 \%$ identity), these were reduced to 593 sequences, partitioned among the species as follows: $A$. braziliensis, 126; A. darlingi, 102; A. marajoara, 170; A. nuneztovari, 106; $A$. triannulatus, 89 . These sequences are available in the hyperlinked Additional file 2: Spreadsheet S1. Additional file 1: Table S5 summarizes these sequences classified into their families, average expression indexes and references to their functional status, when known.
From inspection of Additional file 1: Table S5, it is evident that the most expressed transcripts code for gVAG proteins, which are members of the antigen- 5 family (of unknown function) [31, 32], and the $30 \mathrm{kDa}$ antigen/ Aegyptin protein family, an inhibitor of collagen-induced platelet aggregation [33-36]. The D7 family (acting as kratagonists of biogenic amines and lipid mediators of hemostasis) [37-40], and the anti-thrombin peptide family (cE5/anophelin) are also well expressed [41-45], as are the ATP/ADP hydrolyzing enzymes apyrase/5'nucleotidase (inhibitors of ADP-induced platelet aggregation) [46, 47] and peroxidases, shown to inhibit catecholamine vasoconstrictor effects $[48,49]$.

\section{Apyrases/5'-nucleotidases}

When the EI for members of the apyrase $/ 5^{\prime}$-nucleotidase-coding transcripts are analyzed (Additional file 1: Table S6), two groups of transcripts are apparent, one with EI larger than 25 and another with values smaller than 11. Alignment of their protein sequences with other anopheline proteins from [30] (Additional file 3: Figure S1) shows two distinct clades, named 5Nuc and Apy in the figure, with New World (NW) and Old World (OW) as sub clades. Notably, all products associated with high EI values clustered in the 5Nuc clade, while those with smaller values clustered in the Apy clade (Additional file 3: Figure S1).

The salivary apyrase of Aedes aegypti, belonging to the 5 '-nucleotidase superfamily, is the only mosquito 
salivary apyrase thus far characterized biochemically. The coding gene product was found following chromatographic purification of the activity followed by tryptic digestion of the enzyme, Edman degradation of the products, and PCR-based transcript identification [47]. The product was later cloned and recombinantly expressed, with verification of the apyrase and platelet inhibitor activities [50]. In anophelines the apyrase gene was apparently duplicated early in the anopheline evolution to produce 2 genes, named apyrase and $5^{\prime}$-nucleotidase [31, 32, 51, 52]. However, the substrate specificities of these two enzymes are so far unknown. Perhaps the two enzymes both work as a typical apyrase, hydrolyzing ATP to AMP, or perhaps only one has apyrase activity while the other further hydrolyzes AMP to adenosine. These experiments remain to be done.

\section{Peroxidases}

While Old World anophelines appear to have one gene coding for a salivary peroxidase, New World species appear to have multiple copies of salivary peroxidase-encoding genes [30]. Indeed, the phylogeny reconstruction of the known anopheline peroxidase sequences including those disclosed in this work shows multiple peroxidases for all New World anophelines, including 2 distinct clades for $A$. darlingi containing 6 sequences deriving from at least 3 genes (Additional file 3: Figure S2). Interestingly, two sequences, one from $A$. albimanus and the other from A. braziliensis, form a robust subclade within a clade from solely Old-World species, named NW in Additional file 3: Figure S2. These clades also grouped sequences that have similar expression indexes, as indicated by the symbols,+++ or +++ assigned from low, medium, or high expression indexes.

\section{D7 family}

This family contains one of the first cloned salivary protein from a mosquito [53] and was later found to belong to the odorant binding superfamily [54]. D7 proteins function as kratagonists (agonist binders) of biogenic amines and eicosanoid mediators of inflammation [37]. One A. stephensi protein named hamadarin was shown to inhibit blood clotting [55]. Several of these proteins have been crystalized [38-40]. In A. gambiae there are 3 genes coding for 2 domain proteins (large D7 proteins), and 5 genes coding for short D7 proteins (single domains) [56], arranged in tandem. Interestingly, the last gene coding for the long or short protein was poorly expressed, and it was proposed they may be turning into pseudogenes. The alignment of the long D7 proteins of the Amazonian anophelines with the known anopheline homologues shows a clear clade of New World genes coding for D7-L1 and D7-L2, but no genes coding for the D7-L3 proteins (Additional file 3: Figure S3). Note that the D7-L3 of the New World species A. darlingi and $A$. albimanus, shown in the figure, were previously deducted from their genomes. Previous analysis of the $D 7$ gene cluster in anophelines also, suggested that D7L1 was lost in A. darlingi and A. albimanus, as well as in other Old World anopheline species [30], It is likely this is the case for the four new Amazonian species analyzed here, or, more presumably, the gene was lost by their common ancestor. In fact, the two $A$. marajoara and $A$. braziliensis sequences shown in the phylogenetic tree (Additional file 3: Figure S3) and the additional ones reported in the hyperlinked spreadsheet S1 may be allelic variants.

The alignment of the short D7 proteins, named D7r1 through D7r5, also shows the inexistence of gene expression of the D7r5 from the Amazonian anophelines as deducted from their transcriptomes, although they were found in the genomes of $A$. darlingi and A. albimanus [30]. Two related transcripts from $A$. nuneztovari were found expressed with EI between 1 and 2, although their counterparts are better expressed, with EI values above 10\% (Additional file 3: Figure S4).

\section{Antigen 5 family}

The antigen 5 family is ubiquitously found in sialotranscriptomes of blood sucking arthropods [57]. Several members of this family have been described in anophelines and other mosquitoes, but no mosquito protein of this family has been functionally characterized. In Stomoxys calcitrans, a salivary antigen 5 protein has been found to bind to the Fab region of immunoglobulins and could inhibit complement activation $[58,59]$. A recombinant protein from the triatomine bug, Dipetalogaster maxima, displays superoxide dismutase activity and inhibits platelet activation by low doses of collagen [60]. An antigen 5 protein expressed in the salivary glands of the horse fly, Tabanus yao, exceptionally acquired a disintegrins RGD domain, as well as a hydrophobic pocket that efficiently scavenges leukotrienes; thus defining a bifunctional activity of platelet aggregation inhibitor and leukotriene kratagonist [61, 62]. With this diverse list of functions, it is difficult to predict the adaptive value of these proteins in mosquitoes.

The alignment of the deducted Amazonian anopheline proteins belonging to the antigen 5 family, together with those previously described for anopheline mosquitoes [30], shows that all transcripts cluster within the gVAG clade, while none have been found in the other six clades (Additional file 3: Figure S5). Notice also that the transcripts coding for these proteins are highly expressed, many having EI values above $50 \%$, reaching $100 \%$ in $A$. darlingi and A. braziliensis, meaning it is the most abundant transcript found in the sialotranscriptome of these species. 


\section{$30 \mathrm{kDa}$ antigen/aegyptin family}

The $30 \mathrm{kDa}$ antigen from Ae. aegypti was the first described member of this family [63], and it was later characterized as an inhibitor of collagen-induced platelet aggregation [33, 34]. Anopheline members of this family were identified as glycine-acidic rich proteins [56], later shown to be related to aegyptin, and also to inhibit collagen-induced platelet aggregation [64]. Proteins of this family have a more complex amino terminus and a less complex glycine rich, acidic, carboxy terminus. A protein named Simplagrin was found in salivary transcriptomes of black flies; very divergent from mosquito aegyptins, but conserving the general structure of a complex followed by a less complex amino acid sequence and was also able to inhibit collagen-induced platelet aggregation [65], indicating this protein family was present $\sim 150$ million years ago in the blood-feeding precursors of black flies and mosquitoes. This protein family is unique to Culicoidea. While Aedes mosquitoes have more than one gene of this family expressed in their salivary glands [66, 67], anopheline mosquitoes appear to have only one $[30,56,68-70]$. The sialotranscriptome of Amazonian anophelines indicate these mosquitoes also have a single gene, with possible exception of A. nuneztovari, all with high expression indices (Additional file 3: Figure S6). Whether the two genes from A. nuneztovari result from a gene duplication, or whether it derives from single gene from two cryptic subspecies, remain to be determined.

\section{SG7/Anophensin/Albicin family}

The uniquely anopheline family named SG7 was first discovered in a salivary transcriptome of A. gambiae [31, 32]. A second member of this family was later discovered in $A$. gambiae [56]. Other anopheline species were also shown to express this protein family $[26,69,70]$. A member of the family from $A$. stephensi was characterized as an inhibitor of the kallikrein/bradykinin pathway and named anophensin [71]. Interestingly one SG7 member from $A$. albimanus had demonstrated anti-complement activity and was named albicin [72]. More recently, salivary gland homogenates of $A$. aquasalis were shown to have a similar activity [73]. Interestingly, this family appears to have originated from a gene duplication from an aegyptin-coding gene that evolved to the present day SG7 [30, 74]. Additional file 3: Figure S7 depicts the evolutionary relationships between the known members of the SG7 family with those disclosed in this study.

\section{Sg1 family}

The SG1 family, exclusive of anophelines, is related to the $62 / 34 \mathrm{kDa}$ family of culicines, most arranged as single exon genes and postulated to be acquired by horizontal transmission from a bacterial host early in the evolution of Culicidae [29]. The function of any member of this family is still unknown. Seven members are recognizable in $A$. gambiae, but some (SG1 and SG1a) were missing in $A$. darlingi and $A$. albimanus [30]. The phylogram depicted in Additional file 3: Figure S8 shows the lack of SG1 and SG1a members in all New World species. The figure also shows many variants of the SG1 sub-families within the New World species, but this may be due to allelic variation in the same gene rather than reflecting gene duplications.

\section{cE5/anophelin family}

This is a uniquely anopheline family coding for acidic polypeptides, containing a signal peptide indicative of secretion and a mature molecular weight of $\sim 6.5 \mathrm{kDa}$. The cE5 polypeptide was described during the first sialotranscriptome of A. gambiae [32], while the polypeptide named anophelin was described as the A. albimanus thrombin inhibitor [41, 42]. Alignment of the known members [30] of this family with those found in the present study produces the phylogram shown in Additional file 3: Figure S9. The Amazonian anopheline transcripts coding for members of this family are reasonably well expressed, with EI values ranging from 8 to 57 .

\section{Basic tail family}

This family of secreted polypeptides was first described in Aedes where it has a doublet of positively charged amino acids in its carboxy terminus. However, in $A$. darlingi it was found a homolog without the basic doublet, and similar proteins were found in other Old World anopheline species [29], Additional file 3: Figure S10 shows the alignment of culicine and anopheline sequences, the deducted amino acid motif and the phylogenetic tree derived from the alignment. Despite being a reasonably simple motif, when used to search matches of the non-redundant protein database from the NCBI, with over 160 million entries, only mosquito proteins were retrieved.

\section{Synonymous and non-synonymous single nucleotide polymorphisms}

After mapping the reads to the assembled transcripts of each species transcriptome, it becomes possible to evaluate the rate of synonymous and non-synonymous polymorphism among the different protein classes. Previously we observed an increased rate of non-synonymous polymorphisms in salivary secreted proteins when compared to salivary housekeeping proteins, using transcriptomes from ticks and hematophagous insects [75-78]. Following selection of transcripts that have 100 or more read depth coverage, and with more than 15 transcripts in each functional class, it is observed that the secreted and the unknown class have the highest rate of non-synonymous 
to synonymous polymorphism (Additional file 1: Table S7). This is not an artifact of excess coverage of the transcripts of the secreted class, as the protein synthesis class has high coverage depth and has one of the lowest rates of non-synonymous to synonymous mutations. The high non-synonymous rate observed for the secreted class may reflect a reduced mutational constraint of these proteins, and additionally they may be under positive selection to escape their hosts' immune pressure [79].

\section{Novel Amazonian anophelines viruses}

Metatranscriptomic surveys of diverse invertebrate taxa have been successfully employed to reveal an astonishing diversity of RNA viruses [80]. Here, in parallel to the characterization of the endogenous profile of Anophelines sialotranscriptomes, we effectively identified adventitious RNA sequences corresponding to three novel viruses associated to $A$. triannulatus, $A$. marajoara, and $A$. darlingi. The detected viruses correspond to emergent clades of insect-specific negative-strand single RNA viruses, predominantly hosted by mosquitoes: Orthophasmavirus (Bunyavirales) and Anphevirus (Mononegavirales).

\section{Anopheles triannulatus orthophasmavirus}

The Orthophasmavirus genus (Phasmaviridae) was established by the discovery of two viruses in phantom midges (family Chaoboridae) from North America: Kigluaik phantom orthophasmavirus (KPOPV) and Nome phantom orthophasmavirus (NOMV) [81]. In turn, four additional viruses which clustered with KPOPV and NOMV were identified in mosquitoes and cockroaches from China [82] and dubbed Wuhan mosquito virus 1 and 2 (WMV1 \& WMV2), Shuangao insect virus 2, and Wuchang cockroach virus 1, and incorporated to the genus. Furthermore, three similar viruses derived from metagenomic libraries of magpie moths and pooled Odonata species appear to be related to phasmaviruses [80]. Evolutionary studies suggest that phasmaviruses are sister clades of joniviruses and feraviruses with similar genomic architecture. Phasmaviruses are multipartite ssRNA(-) viruses presenting three genome segments: $\mathrm{S}, \mathrm{M}$, and $\mathrm{L}$ ranging from 1.8-2.2, 2.0-2.8, and 6.5-6.7 $\mathrm{kb}$ in length [83]. Phasmaviruses encode nucleoproteins ( $\mathrm{S}$ segment), glycoproteins (M segment), and RNA-dependent RNA polymerase (RdRPs) (L segment). Additionally, the $\mathrm{S}$ segments appear to encode also NSs proteins at equilocal position with joniviruses. In order to investigate the eventual presence of viral RNA in our datasets, we subjected de novo assemblies to bulk BLASTX searches against the NCBI refseq viral protein database. Interestingly, a $6186 \mathrm{nt}$ contig from $A$. triannulatus showed a significant hit (56\% amino acid (aa) identity; $E$-value $=0$, query coverage = 99\%) with the RdRP of WMV1. Further read mapping and polishing extended the contig into a 6494nt sequence
(RNA 1), supported by 69,379 reads (mean coverage $=$ 1328X), encoding a single 6339 nt ORF. A 2112 aa protein was predicted, presenting a Bunyavirus_RdRP functional domain (910-1225 aa coordinates; pfam04196, E-value = 4.81e-06) (Additional file 3: Figure S11A). To explore this putative RdRP, multiple alignments were generated with representative polymerases of Bunyavirales type species (Additional file 3: Figure S11.B). All major catalytic motifs A-C, including the SDD motif of segment-negative stranded RNA viruses, pre motif A, motif D-E, and conserved N-terminal domain region were detected, suggesting that the predicted RdRP could be functional. In addition, it became evident that the predicted replicase shared significant similarity with the RdRP of the Orthophasmavirus KPOPV. In this scenario, KPOPV segments $\mathrm{M}$ and $\mathrm{S}$ were queried against the $A$. triannulatus sialotranscriptome, and two contigs of $2061 \mathrm{nt}$ and $996 \mathrm{nt}$ were retrieved which were curated into a $2246 \mathrm{nt}$ (RNA 2, mean coverage $=396 \mathrm{X})$ and $2069 \mathrm{nt}(\mathrm{RNA} 3$, mean coverage $=$ 174X). RNA 2 presents a single 2052 nt ORF encoding a putative glycoprotein similar to that of WMV1 (51\% aa identity; E-value $=0$, query coverage $=99 \%$ ). The putative glycoprotein precursor protein was explored in detail, and a signal peptide and cleavage were detected at the NH2 terminal region, three transmembrane sites, three putative glycosylation sites, and a highly conserved Gn/Gc cleavage region at the 217 aa position (Additional file 3: Figure S11.E), suggesting that $\mathrm{Gn}$, as expected, is reduced in length. No evidence of NSm protein was found in RNA2. RNA 3 presents three ORFs, sharing the segment architecture with RNA 3 of WMV1. Only the ORF2 351 aa product shared sequence similarity with the nucleoprotein of WMV1 (52\% aa identity; E-value $=3 \mathrm{e}-107$, query coverage $=98 \%$ ). ORF1 encodes a 123 aa protein with similarity with an unannotated product of WMV1, which has been suggested to be a putative NSs [82]. Lastly, ORF3 encodes a 106 aa product with no similarity with other virus (or insect) proteins. The 3' termini of RNA1-3 shared a $100 \%$ conserved stretch of $14 \mathrm{nt}$, which in Bunyavirales is associated to replication [83]. This exact terminus was observed also in RNA1 of WMV1 (Additional file 3: Figure S11.D). Given the intrinsic structural and functional features detected in the virus sequences, we tentatively propose that they correspond to a new virus, which we dubbed $A$. triannulatus orthophasmavirus (AtOPV). In order to entertain this hypothesis, we generated phylogenetic insights of the putative virus using the predicted RdRP of AtOPV and recognized/proposed members of the Bunyavirales order in multiple alignments and maximum likelihood trees (Additional file 3: Figure S11.F-H). Unequivocally, AtOPV clustered within the Phasmaviridae family (Additional file 3: Figure S11.F). Local topology of the obtained tree suggests that AtOPV clades among a distinctive sub-group of viruses hosted in both mosquitoes 
(Culex tritaeniorhynchus) and midges (Chaoborus trivitattus), including KPOPV, WMV1 and WMV2 (Additional file 3: Figure S11.G-H). Our results expand the distribution of phasmaviruses to South America, and suggest that Anophelines are also host of these insect-specific viruses. Future studies should focus on assessing the prevalence and potential effect of virus presence in $A$. triannulatus.

\section{Novel anphevirus are hosted by A. marajoara and $A$. darlingi}

The recently recognized Anphevirus genus corresponds to an unassigned family within the Mononegavirales order. The last International Committee on Taxonomy of Viruses (ICTV) report [84] indicates there is only one member species: Xincheng anphevirus including the Xincheng mosquito virus (XcMV) associated to A. sinensis, which was described in a large metagenomics study focusing in ssRNA(-) invertebrate viruses [82]. The Anphevirus genus appears to be closely related to members of Bornaviridae and Nyamiviridae family. A number of novel Anphevirus-like viruses have been described recently in West Australian Culex mosquitoes [85], West African A. gambiae mosquitoes [86], and Aedes aegypti mosquitoes [87]. Overall, anpheviruses have been characterized by monosegmented 11-12 kb long negative-stranded RNA genomes encoding in its antigenome six/seven non-overlapping ORFs associated with nucleoproteins $(\mathrm{N})$, small transmembrane proteins (STM), glycoproteins (G1-2), small ZnF proteins (ZnF), and large RdRPs. Anphevirus, like other Mononegavirales, have their ssRNA(-) genomes encapsidated within the nuclecapsid and the RNA polymerase complex. Their RNA genome is used by the RdRP as a template to transcribe discrete mRNAs from the subgenomic genes, which are separated by gene junctions. These mRNAs are capped and polyadenylated. In our bulk BLASTX searches against the NCBI refseq viral protein database, two contigs from $A$. marajoara (12,764 nt) and A. darlingi $(13,063 \mathrm{nt})$ showed significant hits with the RdRP of Bolahun virus (BV, 41-46\% identity, E-value =0). $\mathrm{BV}$ is a recently proposed anphevirus found in A. gambiae mosquitoes from Burkina Faso (variant 1) and Liberia (variant 2), sharing a 94.2\% nt pairwise identity [86].

After contig curation by read mapping, two viral like sequences emerged, harboring the genomic organization of anpheviruses, which we cautiously designated as $A$. marajoara virus (AnMV, 12,265 nt) and $A$. darlingi virus (AnDV, 12,521 nt). The overall pairwise nucleotide identity between AnMV and AnDV was 61\%. Sequence annotation revealed that both sequences presented in their putative antigenomes six ORFs encoding typical anpheviruses predicted gene products in their canonical architecture: 3'-N-STM-G1-G2-ZnF-RdRP-5' (Additional file 3: Figure S12.A). ORF1 of AnMV and AnDV encode a
424-428 aa protein sharing 49.2\% identity among them and a 30-29\% similarity with their closest hit: Aedes anphevirus (AeAV) and Gambiae virus $\mathrm{N}$ proteins, respectively. HHPred searches suggested that both AnMV and AnDV Ns shared protein homology with the p40 nucleoprotein of the Borna disease virus (BoDV-NP, $\mathrm{E}$-value $=3.4 \mathrm{e}-5$, probability $98.3 \%$ ), a feature which was also associated to the AeAV N [87]. ORF2 AnMV and AnDV products are short 120-121 aa with two or one clear transmembrane domains, respectively, sharing a $29 \%$ pairwise aa similarity (the most divergent gene product among both viruses). The putatively 426-457 aa glycoproteins encoded in ORF3 of AnMV and AnDV had no significant hits in both HHPred or BLASTP searches and shared $29.8 \%$ pairwise aa identity among them. ORF4 of AnMV and AnDV encode 647-639 aa glycoproteins, presenting signal peptides in their N-terminus, followed by $\mathrm{O}$ - and $\mathrm{N}$-linked glycosylated sites and two transmembrane domains in the $\mathrm{C}$-terminus of the protein. AnDV presents an additional transmembrane domain in the N-region. Both glycoproteins shared a $71.8 \%$ aa pairwise similarity and $50-51 \%$ aa similarity to the G2 of Bolahun virus and Gambiae virus. In addition, as for the G2 of AeAV [87], both AnMV and AnDV G2 reported significant protein homology with the Human Herpesvirus 1 Envelope Glycoprotein B (HHV1-gB, E-value = 1e-10 and $1 \mathrm{e}-17$, probability 98.1-97.5\%). ORF5 encode a short 46-48 aa product with zinc ribbon type zinc finger domains which were evident when aligned with other anphevirus equilocal products by the significant conservation of Cysteine CXXC motifs (Additional file 3: Figure S12.H). Lastly, ORF6 encodes a ca. 230 kDa RdRP, 2013-2018 aa long, presenting the expected Mononegavirales RdRP (Mononeg_RNA_Pol, E-value $=1.06 \mathrm{e}-63$ ), mRNA capping (M_ne_mRNAcap, $\quad E$-value $=2.54 \mathrm{e}-11$ ) and guanine-7methyltransferase (SAM_MT_MNV_L, E-value $=1.92 \mathrm{e}-10$ ) domains. AnMV and AnDV RdRPs share a $66.9 \%$ aa pairwise identity and $50-51 \%$ similarity with other anpheviruses.

Interestingly, while exploring the intergenic regions of AnMV and AnDV and other anphevirus we were able to pinpoint and characterize a conserved pattern of gene junctions separating the six/seven gene products. A central nucleotide conserved sequence was identified: reading in the antigenome as 3'-UAAAAAACCCGCUA GUUA-5' tentatively functioning as polyadenylation signal terminating each cistron ( $\mathrm{P}(\mathrm{A}) \mathrm{Sig})$, spacer sequence $(\mathrm{Sp})$ and transcription start site (Tstart) of the next mRNA species (Additional file 3: Figure S12.F). With minor variations, this oligomer was found in most gene junctions of all anpheviruses reported yet (Additional file 3: Figure S12 G).

While polishing the AnDV sequence using our datasets we became aware that the virus was present in the 
RNA libraries corresponding to both the $A$. darlingi mosquitoes' samples collected from Macapá (State of Amapá), and Manaus (State of Amazonas) (Additional file 3: Figure S12.I). Moreover, given the low intra-variability of viral reads in each sample (below 0.8\%) we were able to assemble and easily differentiate the RNA virus genomes associated with the mosquitoes of both locations with high confidence (mean coverage of 2195/ 5371X; total virus reads 219,718/538083; 1488/4604 RPKM for AnDV-Mac and AnDV-Man, respectively), which shared an overall $94.7 \%$ sequence identity at the nucleotide level. Additionally, we observed that most polymorphism corresponded to silent SNPs, concomitant with higher sequence similarity for the predicted products at the aa level and accompanied with high sequence conservation at both the 3' leader regions and the conserved gene junctions (Additional file 3: Figure S12 B).

Overall, these observations suggest that the observed variability is biological, and not artifactual. It is interesting that we observed such an elevated level of variation among strains of geographically distinct isolates. It is tempting to suggest that this could be evidence that the A. darlingi mosquito populations of both localities have been separated for an extended time limiting the horizontal transmission and eventual homogenization of virus populations. Future studies should provide insights into the phylogenomics aspects of these viruses.

To assess the evolutionary landscape of the described viruses, we generated phylogenetic insights of the putative anpheviruses using their predicted RdRPs in multiple alignments and maximum likelihood trees with replicase proteins of virus members of the Mononegavirales order (Additional file 3: Figure S12.C). Both AnMV and AnDV RdRPs clustered in a sub-phylloclade of anpheviruses and other unclassified invertebrate viruses, having as divergent sister clades bornaviruses and nyamiviruses, as expected. Local topology of the obtained phylogenetic tree suggests that AnMV and AnDV are closely related and cluster among a sub-clade within anphevirus conformed also by BV and Gambiae virus (Additional file 3: Figure S12.D-E). The branching of AnMV and AnDV within a clade circumscribed to mosquito-specific viruses provides further support of the nature of the detected RNA sequences as evidence of bona fide mosquito viruses. Overall, our results provide evidence of novel anpheviruses associated to the Amazonian anophelines $A$. marajoara and $A$. darlingi.

\section{Conclusions}

Transcriptomic, proteomic, and genomic studies have considerably improved, in the last ten to fifteen years, our understanding of complexity and functions of blood feeding insect salivary proteins. As far as the family
Culicidae is concerned, 12 sialotranscriptomes are currently available, six of which on anopheline mosquitoes: four from Old world (A. gambiae, A. coluzzii, A. funestus, and $A$. stephensi) and two from New world species (A. albimanus and $A$. darlingi) [88]. Despite this considerable progress there is still much to learn since we still completely ignore the function of almost $40 \%$ of the putative mosquito salivary proteins identified thus far. Besides their pharmacological properties, which may be exploited for the development of new drugs (e.g. anti-thrombotics), salivary proteins of blood feeding arthropods may be turned into tools to prevent and/or better control vector borne diseases, for example, through the development of vaccines or biomarkers to evaluate human exposure to vector bites [89-91]. The sialotranscriptome study reported here provided novel data on four New World anopheline species and allowed us to extend our knowledge on the salivary repertoire of A. darlingi. This information may be helpful not only for the characterization of novel activities, but also for the identification of salivary biomarkers to evaluate human exposure to malaria vectors in Central and South America. This may be especially relevant since the $A$. gambiae gSG6, which proved to be a reliable marker of exposure to African [92-94], Asian [95], and Melanesian [96] malaria vectors it is not found in New World anopheline species, as suggested earlier [30] and confirmed by the present study. Additionally, we discovered novel viruses following analysis of the transcriptomes, a procedure that should become standard within future RNAseq studies.

\section{Methods}

Mosquitoes

The five anopheline species used in this study were collected in the Brazilian Amazon region (Fig. 1). The samples of $A$. darlingi were collected in two distinct localities: 1) in the District of Coração ( $\mathrm{N}^{\circ} 01^{\prime}$; W $51^{\circ}$ $\left.10^{\prime}\right)$, located at km 13 of the Duca Serra Road, in the outskirts of the Macapá city, state of Amapá; 2) in the Ramal do Brasileirinho (S 3 ${ }^{\circ} 0^{\prime}$ 08.7"; W 59 52' 16.8") located on the outskirts of city of Manaus, state of Amazonas. These localities are separated $\sim 1100 \mathrm{~km}$ apart and in both localities there is malaria transmission. Samples of A. braziliensis were collected from the outskirts of Macapá city (N $0^{\circ} 1^{\prime} 13.71^{\prime \prime}$; W $51^{\circ} 09^{\prime}$ 47.47"), whereas A. marajoara and A. triannulatus were collected in the Santa Bárbara Farm (N $0^{\circ} 17^{\prime} 28.4$ "; W $50^{\circ} 54^{\prime}$ 07.2"), municipality of Macapá, state of Amapá, Brazil. Specimens of $A$. nuneztovari were captured in the Ramal do Sampaio (S 03 41' 51.8"; W 59 07' 37.5"), municipality of Autazes, state of Amazonas, Brazil. The salivary glands of $A$. darlingi, A. braziliensis, A. marajoara, and $A$. triannulatus used in this study were 
collected from wild mosquitoes (females) captured from the field, whereas those from A. nuneztovari were female descendants from the $F_{1}$ generation reared in the insectary from wild mosquitoes (females) collected from field. The collections were authorized by the System of Authorization and Information in Biodiversity (SISBIO), with permanent license number 38440-1 awarded to VMS.

Adult mosquitoes were captured using a light trap, white Shannon-type, between 18:00 and 22:00 h, and then transferred into cups, properly labeled with locality and collection date. At the end of the captures, the cups containing the mosquitoes were covered with moistened towel paper and transported alive inside tightly closed isothermal boxes to the Laboratório de Genética de Populações e Evolução de Mosquitos Vetores at the Instituto Nacional de Pesquisas da Amazônia (INPA), in Manaus, Brazil. The following day, the specimens were identified using morphological keys of Forattini [15] and Faran and Linthicum [97]. Immediately after, the mosquitoes were cooled in a freezer at $-20^{\circ} \mathrm{C}$ for a few minutes, transferred to an ice-chilled plate, when their salivary glands were dissected on a slide containing a drop of sterile Phosphate Buffered Saline (PBS) pH 7.4, under a stereomicroscope, SV11 model, Carl Zeiss. The salivary glands of each species were immediately transferred to an Eppendorf tube containing $200 \mu \mathrm{L}$ of RNAlater (Thermo Fisher Scientific) solution. Depending on the species analyzed, pools ranging from 80 to 97 pairs of salivary glands were dissected, kept at $4^{\circ} \mathrm{C}$ for $48 \mathrm{~h}$ and then stored at $-80{ }^{\circ} \mathrm{C}$ until the RNA extraction. For more details, see Additional file 1: Table S1.

\section{RNA preparation}

Total RNA from salivary glands was extracted using an RNeasy mini total RNA isolation kit (Qiagen, USA), according to the manufacturer's protocol.

\section{cDNA library construction and sequencing}

Tissue samples were submitted to the North Carolina State Genomic Sciences Laboratory (Raleigh, NC, USA) for Illumina RNA library construction and sequencing. Prior to library construction, RNA integrity, purity, and concentration were assessed using an Agilent 2100 Bioanalyzer with an RNA 6000 Nano Chip (Agilent Technologies, USA). Purification of messenger RNA (mRNA) was performed using the oligo-dT beads provided in the NEBNExt Poly(A) mRNA Magnetic Isolation Module (New England Biolabs, USA). Complementary DNA (cDNA) libraries for Illumina sequencing were constructed using the NEBNext Ultra Directional RNA Library Prep Kit (NEB) and NEBNext Mulitplex Oligos for Illumina (NEB) using the manufacturer-specified protocol. Briefly, the mRNA was chemically fragmented and primed with random oligos for first strand cDNA synthesis. Second strand cDNA synthesis was then carried out with dUTPs to preserve strand orientation information. The double-stranded cDNA was then purified, end repaired, and "a-tailed" for adaptor ligation. Following ligation, the samples were selected a final library size (adapters included) of $400-550 \mathrm{bp}$ using sequential AMPure XP bead isolation (Beckman Coulter, USA). Library enrichment was performed and specific indexes for each sample were added during the protocol-specified PCR amplification. The amplified library fragments were purified and checked for quality and final concentration using an Agilent 2100 Bioanalyzer with a High Sensitivity DNA chip (Agilent Technologies, USA). The final quantified libraries were sequenced in an Illumina HiSeq 2500 DNA sequencer, utilizing 125 bp single end sequencing flow cell with a HiSeq Reagent Kit v4 (Illumina, USA). One lane was run for both A. darlingi libraries, and another lane was run with the remaining four libraries. Flow cell cluster generation for the HiSeq2500 was performed using an automated cBot system (Illumina, USA). The software package Real Time Analysis (RTA), version 1.18.64, was used to generate raw bcl, or base call files, which were then de-multiplexed by sample into fastq files for data submission using bcl2fastq2 v2.16.0 software.

\section{Bioinformatic analysis}

Bioinformatic analyses were conducted following the methods described previously $[76,78]$, with some modifications. Briefly, the fastq files were trimmed of low quality reads $(<20)$, removed from contaminating primer sequences and concatenated for single-ended assembly using the Abyss (using $\mathrm{k}$ parameters from 21 to 91 in 5 fold increments) [98] and Trinity [99] assemblers. These two assemblers were used, because in our previous experience the Abyss assembler produces more novel contigs than the Trinity assembler, but unfortunately it tends to misassembly abundant contigs apparently due to inclusion of products containing introns. However, these abundantly expressed contigs are properly assembled by Trinity. The combined fasta files were further assembled using a iterative blast and CAP3 pipeline as previously described [100]. In the case of $A$. darlingi, the deducted coding sequences (CDS) of the assembled genome (downloaded from Vector Base) [101] were added to the last assembly stage. CDS were extracted based on the existence of a signal peptide in the longer open reading frame (ORF) and by similarities to other proteins found in the Refseq invertebrate database from the National Center for Biotechnology Information (NCBI), proteins from Diptera deposited at NCBI's Genbank and from SwissProt. Accordingly, from $\sim 6$ to 38 thousand CDS were extracted from each of the five assemblies, 
varying in average from 615 to $1200 \mathrm{nt}$ in length (Additional file 1: Table S4). The A. nuneztovari library produced the poorest assembly due to $\sim 25 \%$ rRNA contamination. The reads mapping to rRNA were excluded from the analysis.

Reads for each library were mapped on the deducted CDS using blastn with a word size of 25, 1 gap allowed and $95 \%$ identity or better required. Up to five matches were allowed, if and only if, the scores were the same as the largest score. To compare transcript relative expression among contigs, we used the "expression index" (EI) defined as the number of reads mapped to a particular CDS multiplied by 100 and divided by the largest found number of reads mapped to a single CDS. Detection of single nucleotide polymorphisms (SNP's) were performed with the program Samtools [102] the output of which was used by a program written in visual basic by JMR to assign the synonymous or non-synonymous status of the SNP. The final results were mapped into an excel spreadsheet. Functional classification of the transcripts was achieved by scanning the output of the different blast and rpsblast results using a vocabulary of $\sim 400$ words, the e value of the result and a result coverage $>75 \%$. The classification of "unknown" was given if no match could be found.

Protein alignments were done using clustalX [103], and phylogenies were inferred using the Mega v.6 package [104], The evolutionary history was inferred by using the Maximum Likelihood method based on the best nucleotide substitution matrix available for the alignment, as discovered by the Mega package. The bootstrap consensus tree inferred from 500 replicates is taken to represent the evolutionary history of the taxa analyzed [105]. Other parameters are as indicated in the figure legends.

\section{Virus discovery and analyses}

Virus discovery and annotation was implemented as described in [106]. In brief, de novo assemblies were subjected to BLASTX searches $(E-$ value $=1 \mathrm{e}-5)$ against refseq viral proteins available at ftp://ftp.ncbi.nlm.nih.gov/refseq/release/viral/viral.1.protein.faa.gz. Hits were explored by hand and curated by iterative mapping of reads. ORFs were predicted by ORFinder as implemented in https://www.ncbi.nlm.nih.gov/orffinder/. Functional and structural domains of the predicted gene products were assessed with the NCBI CDD tool https:// www.ncbi.nlm.nih.gov/Structure/cdd/wrpsb.cgi and the HHPred tool https://toolkit.tuebingen.mpg.de/\#/tools/ hhpred. SignalP $4.1 \mathrm{http} / / / \mathrm{www} . c b s . d t u . d k /$ services/SignalP/ was used to detect signal peptides and cleavage regions, TMHMM 2.0 http://www.cbs.dtu.dk/services/ TMHMM-2.0/ for transmembrane predictions, and NetNGlyc 1.0 http://www.cbs.dtu.dk/services/NetNGlyc/ for glycosylation site prediction. Abundance of virus reads was calculated by mapping with standard parameters using Bowtie2 http://bowtie-bio.sourceforge.net/ bowtie2/index.shtml. Phylogenetic insights were based on multiple alignments of replicase proteins with MAFFT v7 https://mafft.cbrc.jp/alignment/software/ with an EINS-i iterative refinement method and BLOSUM64 scoring matrix for amino acids. Phylogenetically uninformative sites were trimmed using the GBlocks tool v.0.91b available as a web server at http://molevol.cmima.csic.es/castresana/Gblocks_server.html. Maximum likelihood trees were generated with FastTree v2.1 http://www.microbesonline.org/fasttree/ with JTT models of amino acid evolution, 1000 tree re-samples and local support values estimated with the Shimodaira-Hasegawa test.

\section{Additional files}

Additional file 1: Tables S1-S7. in a single file. (DOCX $35 \mathrm{~kb}$ )

Additional file 2: Supplemental spreadsheet. (DOCX $11 \mathrm{~kb}$ )

Additional file 3: Figures S1-S12. in a single web format file. (MHT $7748 \mathrm{~kb})$

\section{Abbreviations}

AeAV: Aedes anphevirus; AnDV: A. darlingi virus; AnMV: A. marajoara virus; AtOPV: A. triannulatus orthophasmavirus; BoDV: Borna disease virus; G12: Glycoproteins; HHV1: Human Herpesvirus 1; ICTV: International Committee on Taxonomy of Viruses; KPOPV: Kigluaik phantom orthophasmavirus; NOMV: Nome phantom orthophasmavirus; NP: Nucleoprotein; NW: New World; OW: Old World; RdRP: RNA-dependent RNA polymerase; SISBIO: System of authorization and information in biodiversity; STM: Small transmembrane proteins; WMV: Wuhan mosquito virus; XcMV: Xincheng mosquito virus; ZnF: Small ZnF proteins

\section{Acknowledgements}

The authors thank Dr. Raimundo Nonato Picanço Souto from Federal University of Amapá, Brazil, that kindly provided logistic support during the collections of the anophelines in the Municipality of Macapá, District of Coração and Santa Bárbara Farm, state of Amapá, Brazil. The authors thank Brian Brown, NIH Library Writing Center, for manuscript editing assistance. JMCR was supported by the Intramural Research Program of the National Institute of Allergy and Infectious Diseases. This work utilized the computational resources of the NIH HPC Biowulf cluster (http://hpc.nih.gov).

\section{Funding}

Dr. Vera Margarete Scarpassa was supported by grant 3111/2012-Universal from Fundação de Amparo à Pesquisa do Estado do Amazonas (Brazil). Dr. Bruno Arcà was funded by grant PRIN 2015JXC3JF from the Ministero dell'Istruzione, dell'Università e della Ricerca (Italy. Dr. Jose M. Ribeiro was funded by grant Z01 Al000810-19 from the Division of Intramural Research, National Institute of Allergy and Infectious Diseases (US).

\section{Availability of data and materials}

This project was registered at the National Center for Biotechnology Information (NCBI) under the accession BioProject ID PRJNA428765. Further accessions to Biosample, SRA and TSA are shown in Additional file 1: Table S2. Virus sequences have been deposited in Genbank as follows: $A$. triannulatus orthophasmavirus RNA1-3, MH822966-MH822968; A. darlingi virus, MH822964 and MH822963; A. marajoara virus, MH822965.

\section{Authors' contributions}

VMS conceived the work, supervised the mosquito collections, analyzed the data, wrote most of the introduction, approved final text. HJD Analyzed the data, wrote the virome part of the manuscript, approved final text. RBA 
Participated in the mosquito collections and dissections, approved the final manuscript. JFS Participated in the mosquito collections and dissections, approved the final manuscript. EC Analyzed the data, contributed to the manuscript, approved final text. BA Analyzed the data, contributed to the manuscript, approved final text. JMCR Performed the transcriptome assembly, analyzed the data, contributed to the manuscript, approved final text.

\section{Ethics approval and consent to participate}

The mosquito collections were authorized by the System of Authorization and Information in Biodiversity (SISBIO), with permanent license number 38440-1 awarded to VMS.

\section{Consent for publication}

Not applicable.

\section{Competing interests}

The authors declare that they have no competing interests.

\section{Publisher's Note}

Springer Nature remains neutral with regard to jurisdictional claims in published maps and institutional affiliations.

\section{Author details}

'Laboratório de Genética de Populações e Evolução de Mosquitos Vetores de Malária e Dengue, Coordenação de Biodiversidade, Instituto Nacional de Pesquisas da Amazônia, Manaus, Amazonas, Brazil. ${ }^{2}$ Instituto de Patología Vegetal, Centro de Investigaciones Agropecuarias, Instituto Nacional de Tecnología Agropecuaria (IPAVE-CIAP-INTA), Córdoba, Argentina. ${ }^{3}$ Department of Public Health and Infectious Diseases, Division of Parasitology, Sapienza University of Rome, Rome, Italy. ' Laboratory of Malaria and Vector Research, National Institute of Allergy and Infectious Diseases, Bethesda, MD, USA.

\section{Received: 4 October 2018 Accepted: 18 February 2019}

Published online: 04 March 2019

\section{References}

1. Consoli RAGB, Lourenco de Oliveira R. Principais mosquitos de importancia sanitäria no Brasil. Rio de Janeiro; 1994.

2. Clements AN. Biology of mosquitoes, volume 1: development, nutrition and reproduction. London: Chapman \& Hall; 1992.

3. Harbach RE. The phylogeny and classification of Anopheles. London: IntechOpen Limited; 2013.

4. Sinka ME, Rubio-Palis Y, Manguin S, Patil AP, Temperley WH, Gething PW, Van Boeckel T, Kabaria CW, Harbach RE, Hay SI. The dominant Anopheles vectors of human malaria in the Americas: occurrence data, distribution maps and bionomic precis. Parasit Vectors. 2010;3:72.

5. Deane LM, Causey OR, et al. Rev Serv Espec Saúde Públ. 1948;1:827-965.

6. Arruda M, Carvalho MB, Nussensweig RSMM, Ferreira AW, Cochrane AH. Potential vectors of malaria and their different susceptibility to Plasmodium falciparum and Plasmodium vivax in northern Brazil identified by immunoassay. Amer J Trop Med Hyg. 1986;35:873-81.

7. Tadei WP, Thatcher BD, Santos JM, Scarpassa VM, Rodrigues IB, Rafael MS. Ecologic observations on anopheline vectors of malaria in the Brazilian Amazon. Am J Trop Med Hyg. 1998;59(2):325-35.

8. Tadei WP, Dutary Thatcher B. Malaria vectors in the Brazilian amazon: Anopheles of the subgenus Nyssorhynchus. Revista do Instituto de Medicina Tropical de Sao Paulo. 2000;42(2):87-94.

9. Povoa M, Wirtz R, Lacerda R, Miles M, Warhurst D. Malaria vectors in the municipality of Serra do Navio, state of Amapa, Amazon Region, Brazil. Memorias do Instituto Oswaldo Cruz. 2001;96(2):179-84.

10. Conn JE, Wilkerson RC, Segura MN, de Souza RT, Schlichting CD, Wirtz RA, Povoa MM. Emergence of a new neotropical malaria vector facilitated by human migration and changes in land use. Am J Trop Med Hyg. 2002;66(1):18-22.

11. Galardo AK, Arruda M, D'Almeida Couto AA, Wirtz R, Lounibos LP, Zimmerman $\mathrm{RH}$. Malaria vector incrimination in three rural riverine villages in the Brazilian Amazon. Am J Trop Med Hyg. 2007;76(3):461-9.

12. da Silva-Vasconcelos A, Kato MY, Mourao EN, de Souza RT, Lacerda RN, Sibajev A, Tsouris P, Povoa MM, Momen H, Rosa-Freitas MG. Biting indices, host-seeking activity and natural infection rates of anopheline species in
Boa Vista, Roraima, Brazil from 1996 to 1998. Memorias do Instituto Oswaldo Cruz. 2002;97(2):151-61.

13. Barbosa LM, Souto RN, Ferreira RM, Scarpassa VM. Composition, abundance and aspects of temporal variation in the distribution of Anopheles species in an area of eastern Amazonia. Rev Soc Bras Med Trop. 2014;47(3):313-20.

14. Barbosa LMC, Souto RNP, Dos Anjos Ferreira RM, Scarpassa VM. Behavioral patterns, parity rate and natural infection analysis in anopheline species involved in the transmission of malaria in the northeastern Brazilian Amazon region. Acta Trop. 2016;164:216-25.

15. Forattini O. Culicidologia médica, vol. 2. Sao Paulo: Universidade de Sao Paulo; 2002.

16. Martins-Campos KM, Pinheiro WD, Vitor-Silva S, Siqueira AM, Melo GC, Rodrigues IC, Fe NF, Barbosa M, Tadei WP, Guinovart C, et al. Integrated vector management targeting Anopheles darlingi populations decreases malaria incidence in an unstable transmission area, in the rural Brazilian Amazon. Malar J. 2012;11:351.

17. Lourenco-de-Oliveira R, Guimaraes AE, Arle M, da Silva TF, Castro MG, Motta MA, Deane LM. Anopheline species, some of their habits and relation to malaria in endemic areas of Rondonia State, Amazon region of Brazil. Memorias do Instituto Oswaldo Cruz. 1989;84(4):501-14.

18. Dixon $\mathrm{KE}$, Roberts $\mathrm{DR}$, Llewellyn $\mathrm{CH}$. Epidemiologic study of malaria in a section of Transamazon highway, Brazil. Revista do Instituto de Medicina Tropical de Sao Paulo. 1979;21(6):287-92.

19. Benarroch El. Studies on malaria in Venezuela. Am J Hyg. 1931;14:690-3.

20. Aramburu Guarda J, Ramal Asayag C, Witzig R. Malaria reemergence in the Peruvian Amazon region. Emerg Infect Dis. 1999;5(2):209-15.

21. Galbadón A. Anopheles nuñez-tovari: importante vector y agente de malaria refractaria en Venezuela. Bol Direc Malar Saneam Amb. 1981;21:28-38.

22. Gutierrez LA, Gonzalez JJ, Gomez GF, Castro MI, Rosero DA, Luckhart S, Conn JE, Correa MM. Species composition and natural infectivity of anthropophilic Anopheles (Diptera: Culicidae) in the states of Cordoba and Antioquia, Northwestern Colombia. Memorias do Instituto Oswaldo Cruz. 2009;104(8):1117-24.

23. Tadei WP, Santos JMM, Scarpassa VM, Rodrigues IB. Incidência, distribuição e aspectos ecológicos de espécies de Anopheles (Diptera, Culicidae), em regiões naturais e sob impacto ambiental da Amazônia brasileira. In: E.J. G, G.M. S, E.M. L, L.A. O, editor. Bases Científicas para Estratégias de Preservação e Desenvolvimento da Amazônia, Fatos e Perspectivas, vol. 2. Manaus (AM, Brazil): Instituto Nacional de Pesquisas da Amazônia; 1993. p. 167-96.

24. Foster PG, Bergo ES, Bourke BP, Oliveira TM, Nagaki SS, Sant'Ana DC, Sallum MA. Phylogenetic analysis and DNA-based species confirmation in Anopheles (Nyssorhynchus). PLoS One. 2013;8(2):e54063.

25. Scarpassa VM, Cunha-Machado AS, Saraiva JF. Evidence of new species for malaria vector Anopheles nuneztovari sensu lato in the Brazilian Amazon region. Malar J. 2016;15:205.

26. Calvo E, Andersen J, Francischetti IM, de LCM, deBianchi AG, James AA, Ribeiro JM, Marinotti O. The transcriptome of adult female Anopheles darlingi salivary glands. Insect Mol Biol. 2004;13(1):73-88.

27. Marinotti O, Cerqueira GC, de Almeida LG, Ferro MI, Loreto EL, Zaha A, Teixeira SM, Wespiser AR, Almeida ESA, Schlindwein AD, et al. The genome of Anopheles darlingi, the main neotropical malaria vector. Nucleic Acids Res. 2013;41(15):7387-400.

28. Nanfack Minkeu F, Vernick KD. A Systematic Review of the Natural Virome of Anopheles Mosquitoes. Viruses. 2018;10(5):222.

29. Ribeiro JM, Mans BJ, Arca B. An insight into the sialome of blood-feeding Nematocera. Insect Biochem Mol Biol. 2010;40(11):767-84.

30. Arca B, Lombardo F, Struchiner CJ, Ribeiro JM. Anopheline salivary protein genes and gene families: an evolutionary overview after the whole genome sequence of sixteen Anopheles species. BMC Genomics. 2017;18(1):153.

31. Arca B, Lombardo F, Capurro M, della Torre A, Spanos L, Dimopoulos G, Louis C, James AA, Coluzzi M. Salivary gland-specific gene expression in the malaria vector Anopheles gambiae. Parassitologia. 1999;41(1-3):483-7.

32. Arca B, Lombardo F, de Lara Capurro M, della Torre A, Dimopoulos G, James AA, Coluzzi M. Trapping CDNAs encoding secreted proteins from the salivary glands of the malaria vector Anopheles gambiae. Proc Natl Acad Sci U S A. 1999:96(4):1516-21.

33. Calvo E, Tokumasu F, Marinotti O, Villeval JL, Ribeiro JM, Francischetti IM. Aegyptin, a novel mosquito salivary gland protein, specifically binds to collagen and prevents its interaction with platelet glycoprotein VI, integrin alpha2beta1, and von Willebrand factor. J Biol Chem. 2007; 282(37):26928-38 
34. Calvo E, Tokumasu F, Mizurini DM, McPhie P, Narum DL, Ribeiro JM, Monteiro RQ, Francischetti IM. Aegyptin displays high-affinity for the von Willebrand factor binding site (RGQOGVMGF) in collagen and inhibits carotid thrombus formation in vivo. FEBS J. 2010;277(2):413-27.

35. Mizurini DM, Francischetti IM, Monteiro RQ. Aegyptin inhibits collagen-induced coagulation activation in vitro and thromboembolism in vivo. Biochem Biophys Res Commun. 2013; 436(2):235-9 doi: 210.1016/j.bbrc.2013.1005.1082. Epub 2013 May 1030.

36. Chagas AC, Ramirez $J$, Jasinskiene $N$, James AA, Ribeiro JM, Marinotti O, Calvo E. Collagen-binding protein, Aegyptin, regulates probing time and blood feeding success in the dengue vector mosquito, Aedes aegypti. Proc Natl Acad Sci U S A. 2014;111(19):6946-51.

37. Calvo E, Mans BJ, Andersen JF, Ribeiro JM. Function and evolution of a mosquito salivary protein family. J Biol Chem. 2006;281(4):1935-42.

38. Mans BJ, Calvo E, Ribeiro JM, Andersen JF. The crystal structure of D7r4, a salivary biogenic amine-binding protein from the malaria mosquito Anopheles gambiae. J Biol Chem. 2007;282(50):36626-33.

39. Calvo E, Mans BJ, Ribeiro JM, Andersen JF. Multifunctionality and mechanism of ligand binding in a mosquito antiinflammatory protein. Proc Natl Acad Sci U S A. 2009;106(10):3728-33.

40. Alvarenga PH, Francischetti IM, Calvo E, Sa-Nunes A, Ribeiro JM, Andersen $J F$. The function and three-dimensional structure of a thromboxane $A_{2} /$ cysteinyl leukotriene-binding protein from the saliva of a mosquito vector of the malaria parasite. PLoS Biol. 2010;8(11):e1000547.

41. Valenzuela JG, Francischetti IM, Ribeiro JM. Purification, cloning, and synthesis of a novel salivary anti-thrombin from the mosquito Anopheles albimanus. Biochemistry. 1999;38(34):11209-15.

42. Francischetti IM, Valenzuela JG, Ribeiro JM. Anophelin: kinetics and mechanism of thrombin inhibition. Biochemistry. 1999;38(50):16678-85.

43. Ronca R, Kotsyfakis M, Lombardo F, Rizzo C, Curra C, Ponzi M, Fiorentino G, Ribeiro JM, Arca B. The Anopheles gambiae CE5, a tight- and fast-binding thrombin inhibitor with post-transcriptionally regulated salivary-restricted expression. Insect Biochem Mol Biol. 2012;42(9):610-20.

44. Figueiredo AC, de Sanctis D, Gutierrez-Gallego R, Cereija TB, Macedo-Ribeiro $S$, Fuentes-Prior P, Pereira PJ. Unique thrombin inhibition mechanism by anophelin, an anticoagulant from the malaria vector. Proc Natl Acad Sci U S A. 2012;109(52):E3649-58.

45. Pirone L, Ripoll-Rozada J, Leone M, Ronca R, Lombardo F, Fiorentino G, Andersen JF, Pereira PJB, Arca B, Pedone E. Functional analyses yield detailed insight into the mechanism of thrombin inhibition by the antihemostatic salivary protein CE5 from Anopheles gambiae. J Biol Chem. 2017;292(30):12632-42.

46. Ribeiro JM, Sarkis JJ, Rossignol PA, Spielman A. Salivary apyrase of Aedes aegypti: characterization and secretory fate. Comp Biochem Physiol B Comp Biochem. 1984;79(1):81-6.

47. Champagne DE, Smartt CT, Ribeiro JM, James AA. The salivary gland-specific apyrase of the mosquito Aedes aegypti is a member of the $5^{\prime}$-nucleotidase family. Proc Natl Acad Sci U S A. 1995;92(3):694-8.

48. Ribeiro JM, Nussenzveig RH. The salivary catechol oxidase/peroxidase activities of the mosquito Anopheles albimanus. J Exp Biol. 1993;179:273-87.

49. Ribeiro JM, Valenzuela JG. Purification and cloning of the salivary peroxidase/catechol oxidase of the mosquito Anopheles albimanus. J Exp Biol. 1999;202(Pt 7):809-16.

50. Sun D, McNicol A, James AA, Peng Z. Expression of functional recombinant mosquito salivary apyrase: a potential therapeutic platelet aggregation inhibitor. Platelets. 2006;17(3):178-84.

51. Lombardo F, Di Cristina M, Spanos L, Louis C, Coluzzi M, Arca B. Promoter sequences of the putative Anopheles gambiae apyrase confer salivary gland expression in Drosophila melanogaster. J Biol Chem. 2000; 275(31):23861-8.

52. Lombardo F, Lycett GJ, Lanfrancotti A, Coluzzi M, Arca B. Analysis of apyrase $5^{\prime}$ upstream region validates improved Anopheles gambiae transformation technique. BMC Res Notes. 2009;2:24

53. James AA, Blackmer K, Marinotti O, Ghosn CR, Racioppi JV. Isolation and characterization of the gene expressing the major salivary gland protein of the female mosquito, Aedes aegypti. Mol Biochem Parasitol. 1991;44: 245-54.

54. Valenzuela JG, Charlab R, Gonzalez EC, Miranda-Santos IKF, Marinotti O, Francischetti IM, Ribeiro JMC. The D7 family of salivary proteins in blood sucking Diptera. Insect Mol Biol. 2002;11(2):149-55.
55. Isawa H, Yuda M, Orito Y, Chinzei Y. A mosquito salivary protein inhibits activation of the plasma contact system by binding to factor XII and high molecular weight kininogen. J Biol Chem. 2002;13:13.

56. Arca B, Lombardo F, Valenzuela JG, Francischetti IM, Marinotti O, Coluzzi M, Ribeiro JM. An updated catalogue of salivary gland transcripts in the adult female mosquito, Anopheles gambiae. J Exp Biol. 2005;208(Pt 20):3971-86.

57. Ribeiro JMC, Arca B. From sialomes to the sialoverse: An insight into the salivary potion of blood feeding insects. Adv Insect Physiol. 2009;37:59-118.

58. Swist SL, Wilkerson MJ, Wyatt CR, Broce AB, Kanost MR. Modulation of bovine lymphocyte response by salivary gland extracts of the stable fly, Stomoxys calcitrans (Diptera: Muscidae). J Med Entomol. 2002;39(6):900-7.

59. Ameri M, Wang X, Wilkerson MJ, Kanost MR, Broce AB. An immunoglobulin binding protein (antigen 5) of the stable fly (Diptera: Muscidae) salivary gland stimulates bovine immune responses. J Med Entomol. 2008;45(1):94-101.

60. Assumpcao TC, Ma D, Schwarz A, Reiter K, Santana JM, Andersen JF, Ribeiro JM, Nardone G, Yu LL, Francischetti IM. Salivary Antigen-5/CAP family members are $\mathrm{Cu}^{2+}$-dependent antioxidant enzymes that scavenge $\mathrm{O}_{2}{ }^{-}$and inhibit collagen-induced platelet aggregation and neutrophil oxidative burst. J Biol Chem. 2013;288(20):14341-61.

61. Xu X, Francischetti IM, Lai R, Ribeiro JM, Andersen JF. Structure of protein having inhibitory disintegrin and leukotriene scavenging functions contained in single domain. J Biol Chem. 2012;287(14):10967-76.

62. Ma D, Xu X, An S, Liu H, Yang X, Andersen JF, Wang Y, Tokumasu F, Ribeiro $J M$, Francischetti IM, et al. A novel family of RGD-containing disintegrins (Tablysin-15) from the salivary gland of the horsefly Tabanus yao targets alphallbbeta3 or alphaVbeta3 and inhibits platelet aggregation and angiogenesis. Thromb Haemost. 2011;105(6):1032-45.

63. Peng Z, Xu W, Lam H, Cheng $L$, James AA, Simons FE. A new recombinant mosquito salivary allergen, rAed a 2: allergenicity, clinical relevance, and cross-reactivity. Allergy. 2006;61(4):485-90.

64. Yoshida S, Sudo T, Niimi M, Tao L, Sun B, Kambayashi J, Watanabe H, Luo E, Matsuoka $\mathrm{H}$. Inhibition of collagen-induced platelet aggregation by anopheline antiplatelet protein, a saliva protein from a malaria vector mosquito. Blood. 2008;111(4):2007-14.

65. Chagas AC, McPhie P, San H, Narum D, Reiter K, Tokomasu F, Brayner FA, Alves LC, Ribeiro JM, Calvo E. Simplagrin, a platelet aggregation inhibitor from Simulium nigrimanum salivary glands specifically binds to the Von Willebrand factor receptor in collagen and inhibits carotid thrombus formation in vivo. PLoS Negl Trop Dis. 2014;8(6):e2947.

66. Ribeiro JM, Arca B, Lombardo F, Calvo E, Phan VM, Chandra PK, Wikel SK. An annotated catalogue of salivary gland transcripts in the adult female mosquito, Aedes aegypti. BMC Genomics. 2007;8(1):6.

67. Ribeiro JM, Martin-Martin I, Arca B, Calvo E. A deep insight into the sialome of male and female Aedes aegypti mosquitoes. PLoS One. 2016;11(3):e0151400.

68. Francischetti IM, Valenzuela JG, Pham VM, Garfield MK, Ribeiro JM. Toward a catalog for the transcripts and proteins (sialome) from the salivary gland of the malaria vector Anopheles gambiae. J Exp Biol. 2002;205(Pt 16):2429-51.

69. Valenzuela JG, Francischetti IM, Pham VM, Garfield MK, Ribeiro JM. Exploring the salivary gland transcriptome and proteome of the Anopheles stephensi mosquito. Insect Biochem Mol Biol. 2003;33(7):717-32.

70. Calvo E, Dao A, Pham VM, Ribeiro JM. An insight into the sialome of Anopheles funestus reveals an emerging pattern in anopheline salivary protein families. Insect Biochem Mol Biol. 2007;37(2):164-75.

71. Isawa H, Orito Y, Iwanaga S, Jingushi N, Morita A, Chinzei Y, Yuda M. Identification and characterization of a new kallikrein-kinin system inhibitor from the salivary glands of the malaria vector mosquito Anopheles stephensi. Insect Biochem Mol Biol. 2007;37(5):466-77.

72. Mendes-Sousa AF, Queiroz DC, Vale VF, Ribeiro JM, Valenzuela JG, Gontijo NF, Andersen JF. An inhibitor of the alternative pathway of complement in saliva of New World Anopheline mosquitoes. J Immunol. 2016;197(2):599-610.

73. Mendes-Sousa AF, Vale VF, Queiroz DC, Pereira-Filho AA, da Silva NCS Koerich LB, Moreira LA, Pereira MH, Sant'Anna MR, Araujo RN, et al. Inhibition of the complement system by saliva of Anopheles (Nyssorhynchus) aquasalis. Insect Biochem Mol Biol. 2018;92:12-20.

74. Neafsey DE, Waterhouse RM, Abai MR, Aganezov SS, Alekseyev MA, Allen JE, Amon J, Arca B, Arensburger P, Artemov G, et al. Mosquito genomics. Highly evolvable malaria vectors: the genomes of 16 Anopheles mosquitoes. Science (New York, NY). 2015;347(6217):1258522.

75. Kotsyfakis M, Schwarz A, Erhart J, Ribeiro JM. Tissue- and time-dependent transcription in Ixodes ricinus salivary glands and midguts when blood feeding on the vertebrate host. Sci Rep. 2015;5:9103. 
76. Chagas AC, Calvo E, Rios-Velasquez CM, Pessoa FA, Medeiros JF, Ribeiro JM. A deep insight into the sialotranscriptome of the mosquito, Psorophora albipes. BMC Genomics. 2013;14:875.

77. Schwarz A, Medrano-Mercado N, Schaub GA, Struchiner CJ, Bargues MD Levy MZ, Ribeiro JM. An updated insight into the sialotranscriptome of Triatoma infestans: developmental stage and geographic variations. PLoS Negl Trop Dis. 2014;8(12):e3372.

78. Ribeiro JM, Chagas AC, Pham VM, Lounibos LP, Calvo E. An insight into the sialome of the frog biting fly, Corethrella appendiculata. Insect Biochem Mol Biol. 2014;44:23-32.

79. Arca B, Struchiner CJ, Pham VM, Sferra G, Lombardo F, Pombi M, Ribeiro JM. Positive selection drives accelerated evolution of mosquito salivary genes associated with blood-feeding. Insect Mol Biol. 2014;23(1):122-31.

80. Shi M, Lin XD, Tian JH, Chen LJ, Chen X, Li CX, Qin XC, Li J, Cao JP, Eden JS, et al. Redefining the invertebrate RNA virosphere. Nature. 2016;540(7634): 539-43

81. Ballinger MJ, Bruenn JA, Hay J, Czechowski D, Taylor DJ. Discovery and evolution of bunyavirids in arctic phantom midges and ancient bunyaviridlike sequences in insect genomes. J Virol. 2014:88(16):8783-94.

82. Li CX, Shi M, Tian JH, Lin XD, Kang YJ, Chen L, Qin XC, Xu J, Holmes EC, Zhang YZ. Unprecedented genomic diversity of RNA viruses in arthropods reveals the ancestry of negative-sense RNA viruses. Elife. 2015;4.

83. Junglen S. Evolutionary origin of pathogenic arthropod-borne viruses-a case study in the family Bunyaviridae. Curr Opin Insect Sci. 2016;16:81-6.

84. Amarasinghe GK, Bao Y, Basler CF, Bavari S, Beer M, Bejerman N, Blasdell KR, Bochnowski A, Briese T, Bukreyev A, et al. Taxonomy of the order Mononegavirales: update 2017. Arch Virol. 2017;162(8):2493-504.

85. Shi M, Neville P, Nicholson J, Eden JS, Imrie A, Holmes EC. High-Resolution Metatranscriptomics Reveals the Ecological Dynamics of MosquitoAssociated RNA Viruses in Western Australia. J Virol. 2017;91(17):e00680-17.

86. Fauver JR, Grubaugh ND, Krajacich BJ, Weger-Lucarelli J, Lakin SM, Fakoli LS 3rd, Bolay FK, Diclaro JW 2nd, Dabire KR, Foy BD, et al. West African Anopheles gambiae mosquitoes harbor a taxonomically diverse virome including new insect-specific flaviviruses, mononegaviruses, and totiviruses. Virology. 2016;498:288-99.

87. Parry R, Asgari S. Aedes anphevirus (AeAV): an insect-specific virus distributed worldwide in Aedes aegypti mosquitoes that has complex interplays with Wolbachia and dengue virus infection in cells. J Virol. 2018; 92(17):e00224-18

88. Arcà B, Ribeiro JMC. Saliva of hematophagous insects: a multifaceted toolkit. Curr Opin Insect Sci. 2018;29:102-9.

89. Narasimhan S, Schleicher TR, Fikrig E: Translation of saliva proteins into tools to prevent vector-borne disease transmission. In Arthropod Vector. In: Controller of Disease Transmission. Edited by Wikel SK AS, Dimopoulos G, vol. 2: Elsevier/Academic Press 2017: 249-300.

90. Wd C, Oliveira F, Coutinho-Abreu IV, Kamhawi S, Valenzuela JG. Basic and translational research on sand fly saliva: pharmacology, biomarkers and vaccines. In: Wikel SKAS, Dimopoulos G, editors. Arthropod Vector: Controller of Disease Transmission, vol. 2: Elsevier/Academic Press; 2017. p. 65-89.

91. Manning JE, Morens DM, Kamhawi S, Valenzuela JG, Memoli M. Mosquito saliva: the Hope for a universal arbovirus vaccine? J Infect Dis. 2018;218(1): 7-15.

92. Sagna AB, Gaayeb L, Sarr JB, Senghor S, Poinsignon A, Boutouaba-Combe S, Schacht AM, Hermann E, Faye N, Remoue F, et al. Plasmodium falciparum infection during dry season: IgG responses to Anopheles gambiae salivary gSG6-P1 peptide as sensitive biomarker for malaria risk in Northern Senegal. Malar J. 2013;12:301.

93. Sagna W, Poinsignon A, Remoue F. Epidemiological applications of assessing mosquito exposure in a malaria-endemic area. In: Wikel SKAS, Dimopoulos G, editors. Arthropod Vector: Controller of Disease Transmission, vol. 2: Elsevier/Academic Press; 2017. p. 209-29.

94. Rizzo C, Ronca R, Fiorentino G, Verra F, Mangano V, Poinsignon A, Sirima SB, Nebie I, Lombardo F, Remoue F, et al. Humoral response to the Anopheles gambiae salivary protein gSG6: a serological indicator of exposure to Afrotropical malaria vectors. PLoS One. 2011;6(3):e17980.

95. Ya-Umphan P, Cerqueira D, Cottrell G, Parker DM, Fowkes FJL, Nosten F, Corbel $\mathrm{V}$. Anopheles salivary biomarker as a proxy for estimating Plasmodium falciparum malaria exposure on the Thailand-Myanmar border. Am J Trop Med Hyg. 2018;99(2):350-6.
96. Idris ZM, Chan CW, Mohammed M, Kalkoa M, Taleo G, Junker K, Arcà B, Drakeley C, Kaneko A. Serological measures to assess the efficacy of malaria control programme on Ambae Island, Vanuatu. Parasite Vectors. 2017;10:204.

97. Faran ME, Linthicum KJ. A handbook of the Amazonian species of Anopheles (Nyssorhynchus) (Diptera: Culicidae). Mosquito Systematics. 1981;13:1-81.

98. Birol I, Jackman SD, Nielsen CB, Qian JQ, Varhol R, Stazyk G, Morin RD, Zhao $Y$, Hirst M, Schein JE, et al. De novo transcriptome assembly with ABySS. Bioinformatics (Oxford, England). 2009;25(21):2872-7.

99. Grabherr MG, Haas BJ, Yassour M, Levin JZ, Thompson DA, Amit I, Adiconis X, Fan L, Raychowdhury R, Zeng Q, et al. Full-length transcriptome assembly from RNA-Seq data without a reference genome. Nat Biotechnol. 2011;29(7): 644-52.

100. Karim S, Singh P, Ribeiro JM. A deep insight into the sialotranscriptome of the gulf coast tick, Amblyomma maculatum. PLoS ONE. 2011:6(12):e28525.

101. Megy K, Emrich SJ, Lawson D, Campbell D, Dialynas E, Hughes DS, Koscielny G, Louis C, Maccallum RM, Redmond SN, et al. VectorBase: improvements to a bioinformatics resource for invertebrate vector genomics. Nucleic Acids Res. 2012:40(Database issue):D729-34.

102. Li H, Handsaker B, Wysoker A, Fennell T, Ruan J, Homer N, Marth G, Abecasis G, Durbin R, Genome Project Data Processing S. The Sequence Alignment/ Map format and SAMtools. Bioinformatics (Oxford, England). 2009;25(16): 2078-9.

103. Larkin MA, Blackshields G, Brown NP, Chenna R, McGettigan PA, McWilliam H, Valentin F, Wallace IM, Wilm A, Lopez R, et al. Clustal W and Clustal X version 2.0. Bioinformatics (Oxford, England). 2007:23(21):2947-8.

104. Tamura K, Stecher G, Peterson D, Filipski A, Kumar S. MEGA6: molecular evolutionary genetics analysis version 6.0. Mol Biol Evol. 2013;30(12):2725-9.

105. Felsenstein J. Confidence-limits on phylogenies - an approach using the bootstrap. Evolution. 1985;39(4):783-91.

106. Debat HJ. An RNA Virome associated to the Golden orb-weaver spider Nephila clavipes. Front Microbiol. 2017;8:2097.

Ready to submit your research? Choose BMC and benefit from:

- fast, convenient online submission

- thorough peer review by experienced researchers in your field

- rapid publication on acceptance

- support for research data, including large and complex data types

- gold Open Access which fosters wider collaboration and increased citations

- maximum visibility for your research: over $100 \mathrm{M}$ website views per year

At $\mathrm{BMC}$, research is always in progress.

Learn more biomedcentral.com/submissions 